\title{
Mudanças ocorridas após diagnóstico e tratamento do câncer na perspectiva da criança
}

Changes after the diagnosis and treatment of cancer from the child's perspective Cambios después del diagnóstico y tratamiento del câncer desde la perspectiva del niño

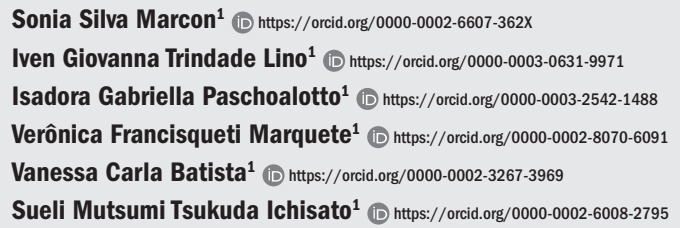

\section{Resumo}

Objetivo: apreender o modo com que crianças com câncer percebem e vivenciam/vivenciaram as mudanças ocorridas em suas vidas.

Métodos: Estudo exploratório-descritivo, de abordagem qualitativa, realizado em Maringá- PR, com oito crianças com idades entre oito e doze anos. Os dados foram coletados por meio de entrevistas audiogravadas e, após, submetidas à análise de conteúdo, modalidade temática.

Resultados: foram identificadas três categorias empíricas: Vivenciando as alterações decorrentes do tratamento; Restabelecendo o convívio social; e Apoio para a superação dos obstáculos.

Conclusão: 0 significado atribuído à doença está associado às mudanças biológicas e sociais, as quais apontam a necessidade de um atendimento individual e diferenciado que permita melhor adaptação à nova fase a ser vivenciada por essas crianças.

\section{Abstract}

Objective: to apprehend the way children with cancer perceive and experience/experienced the changes they had in their lives.

Methods: Exploratory-descriptive study with a qualitative approach, carried out in Maringá-PR, with eight children aged between eight and twelve years. Data were collection took place through audio-recorded interviews and, afterwards, submitted to content analysis, thematic modality.

Results: three empirical categories were identified: Experiencing changes resulting from treatment; Reestablishing social life; and Support to overcome obstacles.

Conclusion: The meaning attributed to the disease is associated with biological and social changes, which point to the need for individual and differentiated care that allows better adaptation to the new phase to be experienced by these children.

\section{Resumen}

Objetivo: comprender cómo los niños con cáncer perciben y experimentan/viven los cambios ocurridos en sus vidas.

Método: estudio exploratorio-descriptivo, de abordaje cualitativo, realizado en Maringá- PR, con ocho niños con edades entre ocho y doce años. Los datos fueron recolectados por medio de entrevistas audio grabadas y después, sometidas al análisis de contenido, modalidad temática.

Resultados: se identificaron tres categorías empíricas: Viviendo las alteraciones derivadas del tratamiento; Restableciendo la convivencia social; y Apoyo para la superación de los obstáculos.

Conclusión: el significado atribuido a la enfermedad está asociado a los cambios biológicos y sociales, que apuntan la necesidad de una atención individual y diferenciada que permita una mejor adaptación a la nueva fase a ser vivida por estos niños.
Descritores

Neoplasias; Saúde da criança; Enfermagem oncológica

Keywords

Cancers; Children's health; Oncology nursing

\section{Descriptores}

Neoplasias; Salud del niño; Enfermería oncológica

\section{Como citar:}

Marcon SS, Lino IG, Paschoalotto IG, Marquete VF, Batista VC, Ichisato SM. [Changes after the diagnosis and treatment of cancer from the child's perspective]. Rev Soc Bras Enferm Ped. 2020;20(1):22-30. Portuguese

\footnotetext{
${ }^{1}$ Universidade Estadual de Maringá, Maringá, PR, Brasil.

Conflitos de interesse: nada a declarar.

Submetido: 2 de Julho de 2019 | Aceito: 29 de Junho de 2020

Autor correspondente: Iven Giovanna Trindade Lino | E-mail: iven_giovanna@hotmail.com

DOI: http://dx.doi.org/10.31508/1676-3793202000004
} 


\section{Introdução}

O câncer infantojuvenil atinge crianças e adolescentes na faixa etária de 0 a 19 anos, e, na maioria dos casos, tem natureza embrionária, podendo ocorrer em qualquer lugar do organismo. Em geral, atinge as células dos tecidos de sustentação e do sistema sanguíneo. ${ }^{(1)}$ Os tipos de câncer pediátrico mais predominantes são leucemia (28\%), sistema nervoso central (26\%) e linfomas $(8 \%) .{ }^{(2)}$ Atualmente, em torno de $80 \%$ das crianças e adolescentes atingidos pela patologia podem ser curados quando diagnosticados precocemente e tratados em centros especializados. ${ }^{(1)}$ Estima-se que, no Brasil, ocorrerão, em cada ano do triênio 2020-2022, novos casos de câncer infantojuvenil, prevendo-se 4.310 casos para o sexo masculino e 4.150 para o sexo feminino. ${ }^{(3)}$

A apresentação clínica do câncer infantil ocorre por meio de sinais e sintomas inespecíficos comuns a outras doenças frequentes na infância, os quais dificultam o diagnóstico. Manifesta-se, geralmente, por meio de sintomas como febre prolongada, vômitos, emagrecimento, sangramentos, adenomegalias generalizadas, dor óssea generalizada e palidez, ou, ainda, por sinais e sintomas de acometimento mais localizado, como cefaléias, alterações na visão, dores abdominais ou osteoarticulares. ${ }^{(4)}$

Assim, a família enfrenta muitos obstáculos até obter o diagnóstico - longos períodos de espera por resultados de exames laboratoriais e de imagem, erros de diagnóstico frente aos sinais e sintomas inespecíficos apresentados pela criança. ${ }^{(5)}$ O diagnóstico e o tratamento englobam inúmeros procedimentos médicos invasivos e dolorosos, terapêuticas agressivas e períodos extensos de internação hospitalar, o que expõe a criança e sua família ao sofrimento físico e mental, permeado por incertezas sobre o que está por vir em relação ao diagnóstico e ao prognóstico. Esse processo é angustiante, costuma ser demorado, e a família se aflige diante de informações incompletas, duvidosas e obscuras.

Diagnosticado, o câncer infantil suscita mudanças repentinas e drásticas na rotina de vida, perpassando o tratamento até o desfecho imprevisível ou a impossibilidade de cura, causando sofrimento à criança, à família e aos profissionais da saúde.(6)

Durante o primeiro ano após o diagnóstico, a criança se esforça para manter seus hábitos de vida, tendo controle sob seu estado de saúde e normalizando a doença e o tratamento. No entanto, prevalece o sentimento de so- lidão e as crianças relatam ter dificuldade com o brincar colaborativo e experimentam sentimentos de não se encaixar com outras crianças. ${ }^{(7)} \mathrm{E}$ isso é preocupante, pois o brincar estimula o desenvolvimento infantil e é fonte de prazer e entretenimento para a criança. ${ }^{(8)}$

O tratamento do câncer infantil compreende procedimentos invasivos e dolorosos, e os fatores envolvidos nesse tratamento se revelam estressores que causam dor, sofrimento, interrupção da escolarização, afastamento do convívio social, além de prejudicar a dinâmica familiar. ${ }^{(8)}$ Além disso, os efeitos adversos das medicações antineoplásicas - alterações no peso, efeitos colaterais de náuseas e vômitos, períodos de debilitação, inapetência, perda dos cabelos, vulnerabilidade a infecções, entre outros - afetam diretamente a qualidade de vida da criança. ${ }^{(9)}$ Assim, por conta de sua complexidade, o câncer pode desencadear, na criança e nos familiares, reações e sentimentos que precisam ser trabalhados sob os mais diversos aspectos, especialmente do psicológico. Ressalta-se que a família também precisa ser acompanhada e assistida por profissionais capacitados, pois ela tem papel fundamental durante todo o tratamento. ${ }^{(10)}$

Nesse contexto, conhecer o modo com que a criança percebe e vivencia as alterações que podem ocorrer nesse período crucial permite que se compreenda o mundo subjetivo que a cerca e, por conseguinte, identificar recursos que possam ajudá-la no enfrentamento da doença. Isto, por sua vez, favorecerá uma assistência de enfermagem mais apropriada e adequada às suas reais necessidades durante todo o processo do adoecer. Diante do exposto, neste estudo o objetivo é o de apreender o modo com que crianças com câncer percebem e vivenciam/vivenciaram as mudanças ocorridas em suas vidas.

\section{Métodos}

Estudo descritivo-exploratório, com abordagem qualitativa, realizado com crianças que atenderam aos seguintes critérios de inclusão: ter vivenciado o diagnóstico de algum tipo de câncer; e residir em Maringá - PR ou região metropolitana. Adotou-se como critério de exclusão: crianças que tinham idade inferior a oito anos e superior a doze. A idade mínima foi definida por se considerar que a criança em idade escolar apresenta melhor entendimento sobre a doença e maior facilidade para expressar sua percepção sobre a experiência. 
As crianças foram localizadas mediante contato com a Rede Feminina de Combate ao Câncer - instituição filantrópica que disponibiliza serviços de enfermagem, nutrição, fisioterapia, psicologia, farmácia, serviço social, terapia ocupacional e serviço voluntário. ${ }^{(11)}$

A aproximação inicial e a interação com as crianças ocorreram a partir de três encontros. Dois deles durante as atividades de lazer realizadas, quinzenalmente, na instituição, as quais eram conduzidas por uma psicóloga e um terapeuta ocupacional, e o outro foi na festa de final de ano, ocasião em que também foi possível estabelecer contato com as mães das crianças e solicitar a participação delas no estudo.

Os dados foram coletados nos domicílios, por meio de entrevistas audiogravadas após consentimento da criança e de sua mãe. As visitas foram previamente agendadas conforme a disponibilidade da criança, da mãe e da pesquisadora, e as entrevistas foram guiadas pela seguinte questão norteadora: “Conte-me como está sendo sua vida após a descoberta da doença". Ressalta-se que, no caso de cinco crianças, as entrevistas foram realizadas em mais de uma visita.

As entrevistas foram transcritas no mesmo dia de sua realização, possibilitando que fossem enriquecidas com informações provenientes de lembranças da pesquisadora sobre o comportamento da criança. O material transcrito foi submetido à análise de conteúdo, modalidade temática ${ }^{(12)}$ cujo objetivo era compreender o sentido das comunicações e suas significações explí- citas e/ou ocultas. Para tanto, foi realizada leitura flutuante das entrevistas, seguida de leituras intensivas, o que permitiu melhor compreensão dos dados obtidos e seu agrupamento em categorias, incluindo-se inferências e correlações com a literatura pertinente.

$\mathrm{O}$ desenvolvimento do estudo atendeu as normas nacionais e internacionais de Ética em Pesquisa envolvendo seres humanos, e foi aprovado pelo Comitê Permanente de Ética em Pesquisa com Seres Humanos da Universidade Estadual de Maringá (CAAE no: 0363.0.093.000-11). Todas as crianças e suas mães assinaram o Termo de Consentimento e Assentimento Livre e Esclarecido em duas vias. A fim de preservar o sigilo e o anonimato na apresentação dos resultados, as crianças foram identificadas por pseudônimos correspondentes à profissão que gostariam de exercer no futuro.

\section{Resultados}

Participaram deste estudo oito crianças, cinco delas tinham o mesmo diagnóstico: leucemia linfoide aguda. Quatro crianças continuam em tratamento e outras quatro em acompanhamento semestral ou anual. No quadro 1 constam, de forma sintética, informações sobre a caracterização dos entrevistados. Ressalta-se que mesmo as duas crianças com diagnóstico há mais de dez anos continuam sendo acompanhadas em serviço

Quadro 1. Caracterização dos sujeitos do estudo

\begin{tabular}{|c|c|c|c|c|c|c|c|c|c|c|}
\hline Crianças & Sexo & Idade & $\begin{array}{c}\text { Série } \\
\text { escolar }\end{array}$ & $\begin{array}{c}\text { Renda } \\
\text { familiar } \\
\text { (SM) }\end{array}$ & Religião & $\begin{array}{l}\text { Atividades de } \\
\text { lazer }\end{array}$ & Diagnóstico & $\begin{array}{c}\text { Tempo de } \\
\text { diagnóstico }\end{array}$ & Tipo de tratamento & Situação atual \\
\hline $\begin{array}{l}\text { Cirurgião } \\
\text { Plástico }\end{array}$ & M & 11 & $5^{a}$ & 4 & Evangélica & Jogos virtuais & $\begin{array}{l}\text { Câncer de } \\
\text { Pulmão }\end{array}$ & $\begin{array}{c}10 \text { anos e } 2 \\
\text { meses }\end{array}$ & Cirurgia + QT + RT & Acompanhamento Anual \\
\hline Professora & $\mathrm{F}$ & 9 & $4^{a}$ & 2 & Evangélica & $\begin{array}{c}\text { Jogos virtuais } \\
\text { e Piscina }\end{array}$ & Retinoblastoma & 6 anos & Cirurgia +QT & Acompanhamento Anual \\
\hline $\begin{array}{l}\text { Jogador de } \\
\text { futebol }\end{array}$ & M & 9 & $4^{a}$ & 1 & Católica & $\begin{array}{c}\text { Jogos virtuais } \\
\text { e TV }\end{array}$ & LLA & 2 anos & QT & QT ciclo 21 dias \\
\hline Bombeiro & M & 12 & $6^{a}$ & 6 & Católica & $\begin{array}{l}\text { Jogos virtuais } \\
\text { e celular }\end{array}$ & LLA & 11 anos & Cirurgia+ QT & Acompanhamento Anual \\
\hline DJ & M & 12 & $6^{a}$ & 3 & Católica & $\begin{array}{l}\text { Jogos virtuais } \\
\text { e celular }\end{array}$ & Retinoblastoma & $\begin{array}{c}2 \text { anos e } 4 \\
\text { meses }\end{array}$ & $\mathrm{QT}+\mathrm{RT}$ & QT ciclo 21 dias \\
\hline $\begin{array}{l}\text { Engenheiro } \\
\text { Mecatrônico }\end{array}$ & M & 11 & $5^{a}$ & 4 & Evangélica & $\begin{array}{l}\text { Jogos virtuais } \\
+ \text { peixes }\end{array}$ & LLA & 6 anos & QT & $\begin{array}{l}\text { Acompanhamento } \\
\text { Semestral }\end{array}$ \\
\hline Atleta & M & 9 & $4^{a}$ & 3 & Católica & Piscina & LLA & 1 ano & QT & $\begin{array}{c}\text { QT semanal+ } \\
\text { Aguarda Transplante }\end{array}$ \\
\hline Enfermeira & $\mathrm{F}$ & 8 & $3^{a}$ & 1 & Católica & $\begin{array}{c}\text { Brincar com } \\
\text { amigas e } \\
\text { passear }\end{array}$ & LLA & 1 ano & QT & QT ciclo 21 dias \\
\hline
\end{tabular}

SM= Salário Mínimo; LLA = Leucemia Linfoide Aguda; QT = Quimioterapia; RT = Radioterapia 
especializado, o que demonstra o quanto esse diagnóstico traz implicações em suas vidas.

As três categorias temáticas que emergiram, a seguir descritas, mostram as mudanças ocorridas após o diagnóstico e as fontes de apoio durante o processo da doença.

\section{Vivenciando as alterações físicas decorrentes do tratamento}

As alterações que acometeram a vida da criança durante o tratamento da doença afetaram-na significativamente. As falas refletem a insegurança com a própria aparência após a queda dos cabelos - efeito da quimioterapia - juntamente com o medo de como as outras crianças iriam reagir diante da nova aparência.

Meu cabelo caiu, mas sei lá, penteava e puxava e caía tudo. Só não gostava que os outros me vissem assim, eu me achava feio - Mas antes (da doença), quando era menor, eu gostava de ficar raspando a cabeça e só deixava um topete. [...] Eu achava que meus amigos[...] iam falar alguma coisa, podiam tirar sarro. Mas isso nunca aconteceu e ninguém nunca falou nada (DJ. 12 anos).

Tinha vergonha de sair na rua. Meu cabelo caiu, daí quando estava no hospital, minha mãe foi lavar e caiu tudo. Depois comecei a usar chapeuzinho, daí cresceu e eu comecei a usar tiara. [...] Ah, eu sentia vergonha por causa que meu cabelo tinha caído. Tinha medo de tirar sarro, mas ninguém tirou (Enfermeira, 8 anos).

As crianças que permaneciam em tratamento, apesar de já terem vivenciado essa experiência, demonstraram, no tom de suas vozes, que conviver novamente com a aparência atual lhes causava receio e medo de serem discriminadas.

Lá no hospital tem crianças iguais a mim, cabelo curto (careca). Quando o meu cabelo começou a cair, ficava ardendo o couro cabeludo, daí eu pedia para minha mãe raspar meu cabelo. Minha mãe falava que eu ficava bonito, mas eu olhava no espelho e me achava horrível. O cabelo caiu todo, então não fui para escola nessa época, porque tinha muita vergonha (Jogador de Futebol, 9 anos ).

Em dois relatos percebe-se que a constituição ontológica da visão aviva, no ser humano, a capacidade de não apenas ver algo, mas de apreender o mundo e de movimentar-se ao encontro das pessoas ao seu redor. Entretanto, as crianças apresentam dificuldades e inseguranças ao lidar com as próteses, necessitando de auxilio e supervisão.
Só enxergo com o olho direito, o esquerdo é uma prótese. Minha mãe que tira a prótese e coloca. Sozinho não consigo, porque tenho medo de me machucar (Bombeiro, 12 anos).

A minha prótese é a única coisa que me incomoda. Às vezes, eu durmo com ela e já tiro sozinha. Mas sempre a minha mãe está por perto (Professora, 9 anos).

Em relação à quimioterapia, os efeitos colaterais são descritos pelas crianças como desgastantes, envolvendo sentimentos, mudanças na dinâmica social e no seu estilo de vida devido à necessidade de viajar até a cidade de referência para o tratamento oncológico.

Não gosto de fazer a quimioterapia, porque passo mal, não consigo comer. Dá muito enjoo, dói muito meu corpo. Minha mãe fala que quando tenho febre, pode dar pneumonia, daí posso morrer, então fico com medo (DJ, 12 anos).

Sinto muito enjoo, dor no corpo inteiro. Daí eles me dão remédio para melhorar. Sofri bastante, sentia dor, canseira, não podia ir para a escola. Quando fiquei internado, não podia vir para casa, tinha que ficar no hospital. Uma vez eu chorei porque queria vir embora, tava com saudades (Jogador de Futebol, 9 anos).

Não obstante, percebe-se, na fala de Enfermeira e de Jogador de Futebol, que a inserção do cateter endovenoso amenizou a angústia e o sofrimento vivenciado diante da necessidade de serem puncionados sempre que a medicação era administrada ou quando era necessário coletar sangue para os exames de rotina.

Tive que colocar o cateter, e quando coloquei estava anestesiada. Eles me deram um negócio para dormir e depois não vi mais nada. Quando acordei, já estava com o cateter. Colocaram para não ficar pegando veia, porque as minhas veias não aguentavam mais, estavam todas estouradas. Eles colocam uma agulha e micropore e o remédio, só sinto dor quando tira a agulha, porque o micropore fica colado em volta e dói... só um pouquinho, e depois passa (Enfermeira, 8 anos).

Quando colocaram o cateter me deram anestesia, fizeram o corte, daí depois teve que costurar. [...] Esse cateter serve para quimioterapia e coletar sangue. Colocaram para não doer mais e também porque não aparecia mais nenhuma veia, estavam todas secas e não dava para coletar sangue. [...]Eu não aguentava mais ficar internado no hospital, porque todo dia coletavam sangue. Agora não dói mais (Jogador de Futebol, 9 anos). 


\section{As mudanças ocorridas e o impacto na esfera social das crianças}

A doença impõe à criança o afastamento de atividades importantes para o seu desenvolvimento, como as brincadeiras, levando-a a desistir de planos para o futuro. A doença gera muitas faltas à escola e o distanciamento dos colegas. Essas crianças enfrentam o medo da discriminação dos colegas de classe e do ) tratamento diferenciado.

Na escola, poucas pessoas sabem. Daí me tratam normal, porque falei no começo do ano, aí nem lembram mais. No começo, a notícia se espalhou, porque quase ninguém tinha visto alguém com a doença. Aí depois, ficou normal. Eles perguntaram como foi, se eu tinha alguma coisa, aí eu respondia só o que perguntavam (Cirurgião Plástico, 11 anos).

Estou indo bem na escola, mas agora não está dando para eu ir, porque me dá bastante febre e tenho que ficar o tempo todo sem ir para a escola. Os amigos me tratam bem, ninguém tira sarro. Mas não fui para escola nessa época, senão não ia passar de ano por muita falta. Logo que descobri a doença, eu parei de ir para a escola (Jogador de Futebol, 9 anos).

Após o diagnóstico da doença, a criança vivencia o processo escolar de forma única e individual e seu comportamento, muitas vezes, é influenciado pelas atitudes de outros alunos. Os sintomas da doença impedem que ela passe por esse período escolar da mesma forma que as outras crianças da classe.

Conheço todo mundo da minha sala e das outras salas. Sou amigo de quase todo mundo. A maioria não sabe do meu problema. Às vezes, estou passando mal, daí tenho que falar para as professoras e venho para casa. Várias vezes saiu sangue do meu nariz durante a aula, mas só contei para alguns colegas, porque começaram a perguntar por que saía sangue. Falei que tinha leucemia, que era câncer no sangue. É impossível não tirar sarro naquela sala[...] Eles não falam sobre o que aconteceu comigo, eles ficam falando por brincadeira, não por mal, e assim vai; mas isso não me prejudica (Engenheiro Mecatrônico, 11 anos).

Outras crianças expressam com muita clareza as atividades que não podem mais desenvolver devido às limitações impostas pela doença e seu tratamento, $\mathrm{o}$ que as impede de viver a infância em plenitude.

Sinto vontade, mas não posso nadar na piscina por causa do cateter. O médico e as enfermeiras falam que é porque pode dar infecção, porque entra muita gente ao mesmo tempo na piscina. Mais uma coisa, não posso jogar bola.
Mas de vez em quando eu jogo videogame. Na verdade, nem brinco muito. Quando vou brincar, meu primo vem aqui e meus amigos só brincam com ele, porque eles têm medo de me machucar, por causa da minha doença (Jogador de futebol, 9 anos).

Cabe ressaltar que as limitações persistem mesmo nos casos em que tenham passado vários anos do diagnóstico, e as crianças se mostrem bem resolvidas em relação à necessidade de usar prótese.

Eu sinto que sou diferente, não posso jogar futebol, wôlei, basquete... Por que não pode acertar no olho né? Sinto falta de brincar. Esses dias, eu fui jogar queima e acertou meu olho... E todo mundo ficou preocupado (Professora, 9 anos).

DJ, por sua vez, relata que a limitação não decorre somente do fato de não poder brincar, mas envolve aspectos do dia a dia, por exemplo, não poder erguer objetos pesados ou realizar atividades que exijam esforço físico.

O ruim é que não posso fazer várias coisas, só jogar videogame. Não posso pegar peso e nem fazer esforço físico, entrar na piscina; não posso bater o cateter. Não posso me machucar, e por causa do cateter (DJ, 12 anos).

\section{Encontrando apoio para superação dos obstáculos}

Nos relatos das crianças foram identificadas algumas fontes de apoio consideradas essenciais para superar as barreiras impostas pelo convívio com a doença.

Olha, sem minha mãe, acho que não estava aqui. Ela é tudo para mim. Sem minha família, não sou nada, não existiria. Minha irmã e eu brigamos às vezes, mas sinto muita falta dela, não podia entrar porque era pequena. Meu pai me visitava todo dia. Meus parentes me visitaram (Engenheiro Mecatrônico, 11 anos).

A relação com meus pais é boa, melhor agora. Quando minha mãe vai comigo para Curitiba, nós ficamos mais juntos. Ela faz várias coisas, cuida de mim, faz as comidas que eu gosto, me trata normal como meu irmão. Eu pergunto se ela gosta mais de mim ou dele e ela sempre diz que gosta igual dos dois. Quando descobriu minha doença, ela chorou bastante, agora ela chora quando eu fico muito mal. Meu pai é legal, eu brinco com ele de bola, ele me leva para dormir, me cobre, apaga a luz e liga o ventilador para mim... Coisa que antes ele não fazia. Eles sempre me falam dando apoio, que eu vou aguentar e que no final, terei uma vitória. Eu concordo (Atleta, 9 anos). 
Independentemente de qual seja a religião, as crianças experimentam o sentimento e o poder da fé.

Eu oro pedindo para Deus que abençoe meu pai, minha mãe, minha família. Peço para que a doença não volte, porque várias pessoas que conheço, a doença voltou. Peço para que nunca volte e que eu sare logo, pois o meu maior medo é que isso volte, porque se voltar eu tenho que ir para Curitiba. Mas eu peço para Deus que não volte e eu tenho fé (Engenheiro Mecatrônico, 11 anos).

Eu peço para Deus todos os dias para ele me curar, não me fazer sofrer mais e nem os meus pais (Professora, 9 anos).

Eu tenho medo de morrer, porque já vi vários amigos meus que tinham leucemia, indo embora. Rezo todos os dias para que dê tudo certo no transplante. Na hora que o médico estiver mexendo comigo, que Deus esteja com ele, que vai dar tudo certo, que eu vou poder brincar e fazer tudo que tenho vontade (Atleta, 9 anos).

Com o apoio prestado pela instituição filantrópica, de modo geral as crianças se sentem acolhidas e assistidas, o que supre, pelo menos em parte, as necessidades e expectativas suas e de suas famílias.

Lá na rede, eles fazem de tudo pela gente... Dão cesta básica, dão um monte de coisas, a gente brinca muito lá e, de vez em quando, nós vamos para algum lugar passear. Se não fosse a Rede, nós estaríamos passando algumas necessidades (Jogador de futebol, 9 anos).

A rede ajuda muito a minha família, dá cesta básica todo mês. Dão remédio, um monte de coisas. Às vezes, minha mãe precisa de alguma coisa e eles sempre correm atrás. Gosto muito de ir nas atividades que eles fazem com as crianças. Eles ligam e falam para a gente ir lá, que eles vão vir buscar. Toda vez que vamos é diferente, a gente brinca, come lanche. Da última vez, assistimos filme, eles conversam bastante também ( $D J, 12$ anos).

A Rede antes ajudava meu pai a pagar até o aluguel. Agora não ajudam mais porque estão sem recursos, mas dão cestas básicas e outras coisas (Atleta, 9 anos).

Eu vou lá brincar, às vezes tem festa. Fico brincando com as tias. Eles dão cesta básica e pagam as contas. Ligam e perguntam se estou bem (Enfermeira, 8 anos).

\section{Discussão}

Os relatos mostram que o tratamento provocou mudanças repentinas, com grande impacto na rotina diária. Todas as mudanças, passageiras ou permanentes, como o uso de prótese que acompanhará a criança por toda sua vida, foram vivenciadas com dor e sofrimento. Para algumas crianças, por exemplo, a alopecia (perda dos cabelos) foi marcante e trouxe desconforto devido à alteração física de sua imagem corporal. Contudo, o sofrimento vivenciado nessa modificação foi ofuscado pela realidade do presente ou atenuado com o passar do tempo.

As crianças, às vezes, associaram a imagem corporal à sua própria identidade, representando a forma com que se viam em seu ambiente. Por esta razão, em alguns momentos a tristeza fez parte de sua vida, ao se sentirem diferentes de seus pares. Estudo realizado com crianças hospitalizadas em unidade de oncologia pediátrica, em Pernambuco, mostrou que as alterações da autoimagem representavam importante fonte de sofrimento, principalmente as geradas pela alopecia, as quais denunciavam, visualmente, a sua condição de doente. $^{(13)}$

Nas falas de Bombeiro e Professora nota-se que a utilização da prótese ocular, além de alterar a sua imagem corporal em uma importante fase do seu crescimento e desenvolvimento, também os impedia de executar pequenas tarefas, tornando-os dependentes de seus familiares. Assim, a perda da visão - sequela imposta pela doença - foi considerada fator definitivo de sofrimento em suas vidas.

O período do tratamento antineoplásico foi descrito pelas crianças como fase marcante da doença, pois, além de afetar seu corpo, comprometeu o sistema vascular periférico, dificultando o acesso venoso, o que causava dor e sofrimento ao ser realizado. Ademais, as drogas quimioterápicas podem alterar o paladar, reduzir a sua percepção ou mesmo torná-lo desagradável, comprometendo a ingestão alimentar, além de provocar ressecamento da mucosa oral, náuseas e/ou vômitos. ${ }^{(4)}$

Destaca-se a necessidade de desenvolver estratégias que auxiliem as crianças a enfrentar o câncer e minimizem as condições estressantes a que estão expostas. Estudo realizado no Sri Lanka identificou, como método mais útil para que isso aconteça, a integração familiar, a cooperação e o otimismo frente à situação, aspectos que podem auxiliar os programas voltados ao relaxamento e aconselhamento. ${ }^{(14)}$

O estado nutricional é essencial para crianças com Câncer, pois lhes permite lidar melhor com o tratamen- 
to intensivo. Ainda, a síndrome da anorexia-caquexia do câncer está relacionada à desnutrição - um fator de risco para os desfechos da doença, pois aumenta a suscetibilidade a infecções e reduz a sobrevida. Alteração nos níveis dos hormônios relacionados à regulação da ingestão alimentar, como a grelina e leptina, foram relatados em uma variedade de cânceres. ${ }^{(15)}$

Os efeitos colaterais do tratamento incluem, além da alteração nos hábitos alimentares, sentimentos de medo e angústia, estabelecendo uma relação direta entre não desejar seguir corretamente a terapêutica proposta e a possibilidade de morrer. Ou seja, o estigma da morte imposto pela doença permeia as vidas dos acometidos. ${ }^{(13)}$ Na linguagem da criança, destaca-se a importância de a mesma ser informada sobre o diagnóstico, tratamento e procedimentos a que será submetida. Dessa forma, o sofrimento desencadeado pelo desconhecido pode ser amenizado por meio de orientações sobre os acontecimentos futuros que poderão ou terão que enfrentar, por exemplo, a inserção do cateter para alívio da dor a cada nova punção.

Estudo realizado com crianças hospitalizadas, em Pernambuco, constatou que quanto mais tranquilas e informadas as famílias se apresentavam, mais a criança reconhecia sua condição, aceitava melhor os procedimentos e os enfrentava de forma mais segura, apesar das situações estressoras. ${ }^{(13)}$ Isto reforça a importância de as crianças conhecerem as características fundamentais de sua doença e entenderem todos os procedimentos pelos quais passarão, a fim de diminuir o medo e a ansiedade perante o desconhecido.

Considerando esse contexto, cabe aos pais intermediar informações de maneira que a criança coopere e aceite o tratamento. ${ }^{(16)}$ Nessa direção, estudo constatou que na comunicação e interação com a criança com câncer, a família se empenha para não expressar mensagens verbais e não verbais desanimadoras, e sim de superação e esperança, a fim de ajudar a criança a enfrentar a situação e a ter esperança na cura da doença. Ou seja, as interações da família com a criança são quase sempre permeadas por uma comunicação positiva, caracterizada pela presença de apoio informacional e emocional, e sempre no sentido de ressaltar os benefícios do tratamento. ${ }^{(5)}$

Não se pode deixar de considerar que, para a criança, a doença é um evento que altera as condições psicológicas e sociais, criando sentimentos de medo, angústia e, muitas vezes, até de pavor, decorrentes da dor e dos procedimentos que são adotados. É um acontecimento considerado violento, podendo afetá-la seriamente, traumatizando-a para o resto da vida .(17)

Com a doença, a rotina das crianças vai, aos poucos, sendo modificada por atividades que não faziam parte do seu mundo, como as visitas ao hospital, que tomam o lugar do cotidiano escolar por exemplo. Nessas circunstâncias, é importante que o convívio social da criança seja mantido, e também seus relacionamentos e compromissos antigos, pois é um momento em que necessitará do apoio de pessoas próximas. Esses vínculos são capazes de criar bases sólidas e necessárias para o fortalecimento do paciente na luta contra a doença.

No relato de Jogador de Futebol foi possível observar sua emoção ao relembrar sua vida escolar antes da doença. Ao dizer: "logo que descobri a doença, eu parei de ir para escola", emocionou-se novamente, sua voz ficou trêmula, e a fala embargada impediu-o de prosseguir. Naquele momento, seu olhar voltou-se para o chão e ele permaneceu em silêncio, como querendo guardar para si as lembranças do tempo feliz que passara com os amigos na escola.

Deveras, o adoecimento por câncer pode inviabilizar a manutenção da rotina da criança e repercutir em sua vida escolar. Os principais pontos conflitantes no cenário social estão direta ou indiretamente relacionados à escola, posto que, neste cenário, a criança adquire identidade e importância própria, ou seja, deixa de ser o filho de alguém para ser ele mesmo. Assim, se não está bem nesse ambiente, isto se refletirá em sua vida global. Ademais, as faltas por causa do extenso período de tratamento e internações, ou mesmo o fato de a criança não estar bem devido aos efeitos colaterais do tratamento, constituem um problema no ambiente escolar, interrompendo a vida social, prejudicando sua socialização e o aprendizado. ${ }^{(18)}$ Tal problemática, nem sempre explícita, gera dificuldades em relação ao tratamento com os outros alunos e os professores que utilizam estereótipos para rotular o sujeito, associando a doença oncológica à morte. ${ }^{(18)}$

Durante o período de adoecimento, a criança necessita de apoio, atenção e compreensão por parte de todos que estão ao seu redor, para que possa se manter emocionalmente estável para enfrentar os desafios causados pela doença. A importância do apoio 
durante a fase do tratamento é explicitada na fala de Engenheiro Mecatrônico, que se sente feliz por perceber que tem vários amigos na escola. Por outro lado, observou-se que ele se esforçava para aceitar as brincadeiras dos colegas, embora sua expressão corporal (gestos negativos com a cabeça) denunciava que tais brincadeiras nem sempre eram bem-vindas.

O suporte social é fundamental para o desenvolvimento do otimismo em relação aos resultados do tratamento em pacientes oncológicos, embora, muitas vezes, a doença diminua a capacidade de a criança adaptar-se socialmente, podendo desencadear consequências negativas no futuro. ${ }^{(19)}$ Estudo realizado na Coréia do Sul, com sobreviventes do câncer infantil, detectou que após o tratamento alguns vivenciaram dificuldades de adaptação social, decorrentes do preconceito ou tratamento discriminatório, e, com isto, tornaram-se socialmente retraídos e desajeitados. ${ }^{(19)}$

Destaca-se que crianças em tratamento de câncer, na maioria das vezes têm suas relações sociais e o brincar substituídos pelo medo e pela insegurança que a doença impõe. O medo e a consciência das limitações impostas pela doença e seu tratamento são explicitados com frequência nos relatos. Jogador de Futebol, por exemplo, com semblante entristecido pela situação vivenciada, apontou diversas atividades que não podia realizar devido à condição clínica em que se encontrava.

Não poder brincar é percebido como algo negativo pelas crianças, as quais podem sentir-se diferentes dos demais. Brincar faz parte do seu mundo ${ }^{(8,20)} \mathrm{e}$, durante o tratamento, além das limitações em poder brincar, a criança poderá experimentar sentimentos de ansiedade, estresse e isolamento social. Nesse contexto, é fundamental que cada membro da equipe profissional incorpore brincadeiras criativas nas rotinas hospitalares diárias, para reduzir estes sentimentos e melhorar a qualidade de vida do paciente. ${ }^{(21)}$

Outro aspecto se refere aos cuidados prestados pelos pais após a descoberta do diagnóstico, os quais foram alterados e intensificados, pois passaram a ser marcados pela riqueza de detalhes. A presença constante do familiar durante esse processo faz a criança sentir-se mais segura e protegida, podendo reagir positivamente ao sofrimento causado pela doença. Durante as entrevistas foi possível evidenciar o brilho no olhar das crianças ao citarem a presença de seus pais em suas vidas, refletindo o amor incondicional que se fortaleceu diante do adoecimento.

A adaptação à nova realidade depende de fatores como o apoio familiar, religioso e social entre outros. ${ }^{(22)}$ Com o aparecimento da doença, os pais começam a superproteger os filhos, por medo de perdê-los, devido ao estigma que a doença traz, pois, para muitos, a palavra câncer constitui sinônimo de dor, sofrimento e morte. A superproteção também ocorre como forma de compensação por todo o sofrimento causado pelo tratamento. ${ }^{(23)}$

Em geral, os familiares querem acompanhar o filho durante todo o processo da doença e, no caso específico do câncer, o impacto do diagnóstico é tão grande, e vivido com tanto sofrimento e intensidade, que os familiares desejam estar presentes para aumentar os momentos de convívio, ${ }^{(23)}$ pois, o medo da morte está sempre acompanhando essa vivência.

Outra fonte de apoio mencionada pelas crianças foi a religião. Todas as crianças do estudo revelaram que a espiritualidade constituiu-se em importante recurso para o enfrentamento do adoecimento. Por meio da religião conseguiam reorganizar suas experiências e buscar auxílio para suportar os momentos de dor, sofrimento e o medo. A fé e a religião incentivam o pensamento positivo de visualizar o futuro sem a doença e se configura em um apoio para superar as dificuldades. ${ }^{(22)}$

Por fim, a estrutura da instituição foi citada por algumas crianças como espaço agradável, confortável e de extrema importância para as novas experiências, o que a configura como um recurso essencial para auxiliá-las nesse período. Além disso, o suporte institucional tem importante papel para a criança e família no adoecimento. Isto porque o apoio e o comprometimento de uma equipe multiprofissional e de diversos setores da sociedade são fundamentais para uma boa resposta ao itinerário terapêutico. Nesse sentido, é fundamental que os pais e os cuidadores recebam avaliações contínuas de suas necessidades de saúde mental e tenham acesso a intervenções apropriadas para otimizar o bem-estar dos pais, da criança e da família. ${ }^{(23)}$

Salienta-se que as instituições de apoio são imprescindíveis na vida dessas crianças, pois as ajuda a superar as dificuldades decorrentes da convivência com a doença, especialmente nos casos em que a família também convive com dificuldades econômicas. ${ }^{(19)}$ 


\section{Conclusão}

Os resultados deste estudo evidenciaram o intenso sofrimento experienciado pela criança que vivencia a condição de estar doente e por aqueles com quem convivem, em especial os familiares mais próximos. Foi possível apreender as percepções em relação às dificuldades, necessidades e expectativas durante todo o percurso da doença. O significado que as crianças atribuem à doença está associado às mudanças biológicas e sociais, o que constitui indicativo da necessidade de um atendimento diferenciado, de modo a permitir que experimentem uma melhor adaptação à nova realidade. Diante disso, faz-se necessário um acompanhamento mais individualizado junto à criança que vivencia o diagnóstico de câncer e sua família, por uma equipe de saúde que compreenda e valorize os aspectos que envolvem o processo de adoecimento que é marcado por instabilidade na vida cotidiana e por exigências diferenciadas de cuidado. Assim, mediante a escuta direta de quem experiencia a doença - a criança e sua família - é que os profissionais de saúde poderão encontrar estratégias que, além de facilitar os cuidados, os tornem mais adequados às reais necessidades das crianças e suas famílias.

\section{Contribuições}

Marcon SS, Lino IGT, Paschoalotto IG, Marquete VF, Batista VC e Ichisato SMT colaboraram com a concepção e projeto; análise e interpretação dos dados; redação do artigo e revisão crítica relevante do conteúdo intelectual e aprovação final da versão a ser publicada.

\section{Referências}

1. Instituto Nacional de Câncer JoséAlencar Gomes da Silva. Tipos de câncer [Internet]. Rio de Janeiro (R)): INCA, 2019 [cited 2020 Jul 17].Available from: https://mww.inca.gov.br/tipos-de-cancer
2. American Cancer Society. Risk factors and causes of childhood cancer [Internet]. Atlanta (USA): American Cancer Society, 2019 [cited 2020 Jul 17]. Available from: https://www. cancer.org/cancer/cancerin-children/risk-factors-and-causes.html

3. Brasil. Ministério da Saúde. Instituto Nacional de Câncer. Coordenação de Prevenção e Vigilância de Câncer. Estimativa 2020: incidência de câncer no Brasil. Rio de Janeiro (RJ): INCA; 2020.

4. Brasil. Ministério da Saúde. Secretaria de Atenção à Saúde. Protocolo de diagnóstico precoce para oncologia pediátrica. Brasília (DF): Ministério da Saúde, 2017.

5. Borges AA, Dupas G. Comunicação entre família e criança: significados da interação em situação de câncer infantil. Cienc Cuid Saude. 2016;15(4):731-7.

6. Pagung LB, Canal CP, Missawa DD, Motta AB. Estratégias de enfrentamento e otimismo de crianças com cancer e criança sem cancer. Rev Psicol Saúde. 2017;9(3):33-46.

7. Enskar K, Darcy L, Bjork M. Young children's experiences of living an everyday life with cancer - a three year interview study. Eur J Oncol Nurs. 2019;39,1-9.

8. Silva LF, Cabral IE. 0 resgate do prazer de brincar da criança com câncer no espaço hospitalar. Rev Bras Enferm. 2015;68(3):391-97.

9. Anjos C, Santo FH, Carvalho EM. 0 câncer infantil no âmbito familiar: revisão integrativa. Rev Min Enf. 2015;19(1):227-40.

10. Landier W, Ahern J, Barakat L, Bhatia S, Bingen KM, Bondurant PG, et al. Patient/ family education for newly diagnosed pediatric oncology patients. J Pediatr Oncol Nurs. 2016;33(6):422-31.

11. Rede Feminina de Combate ao Câncer. Rede Regional de Maringá [Internet]. Maringá (PR): RFCC; 2019 [cited 2020 Jul 17]. Available from: https://rfccmaringa.org.br/quem-somos

12. Bardin L. Análise de conteúdo. São Paulo: Edições; 70; 2011.

13. Emidio SC, Morais RJ, Oliveira PN, Bezerra RS. Percepção de crianças hospitalizadas acerca do tratamento oncológico. Rev Pesqui Cuid Fundam. 2018;10(4):1141-9.

14. Padeniya RN, Thushari G, Nissanka DH, Shashika C, Munasinghe DH, et al. Maternal coping strategies in response to child's oncological diseases in Sri Lanka. Acta Oncol. 2020:1-6.

15. Fayh AP, Bezerra AD, Friedman R. Appetite hormones in children and adolescents with cancer: a systematic review of observational studies. Nutr Hosp. 2018;35:201-10.

16. Korsvold L, Mellblom AV, Lie HC, Ruud E, Loge JH, Finset A. Patient-provider communication about the emotional cues and concerns of adolescent and young adult patients and their family members when receiving a diagnosis of cancer. Patient Educ Couns. 2016;99(10):1576-83.

17. Otmani N, Khattab M. Informational support in pediatric oncology: review of the challenges among arab families. J Cancer Educ. 2018;33(4):732-6.

18. Freitas NB, Santos JL, Estanislau AM, Palitot RM, Fonsêca PN. As percepções das crianças e adolescentes com câncer sobre a reinserção escolar. Rev Psicopedag. 2016;33(101):17582.

19. Kim Y, Lee KS, Koh KN . Difficulties faced by long-term childhood cancer survivors: a qualitative study. Eur J Oncol Nurs. 2018;36:129-34.

20. Burns-Nader S, Hernandez-Reif M. Facilitating play for hospitalized children through child life services. Child Health Care. 2015;45:1-21.

21. Schleisman A, Mahon E. Creative play: a nursing intervention for children and adults with câncer. Clin J Oncol Nurs. 2018;22(2):137-40.

22. Alves DA, Silva LG, Delmondes GA, Delmondes GA, Lemos ICS, Kerntopf MR, et al. Cuidador de criança com câncer: religiosidade e espiritualidade como mecanismos de enfrentamento. Rev Cuid. 2016;7(2):1318-24.

23. Kearney JA, Salley CG, Muriel AC. Standards of psychosocial care for parents of children with cancer. Pediatr Blood Cancer. 2015; 62(Suppl 5):632-83. 